\title{
Colonização, Guerra e Saúde Mental: Fanon, Martín-Baró e as Implicações para a Psicologia Brasileira*
}

\author{
Pedro Henrique Antunes da $\operatorname{Costa}^{1,{ }^{* *}}$ (1) \& Kíssila Teixeira $\operatorname{Mendes}^{2}$ (1) \\ ${ }^{1}$ Universidade de Brasília, Brasília, DF, Brasil \\ ${ }^{2}$ Universidade Federal de Juiz de Fora, Juiz de Fora, MG, Brasil
}

\begin{abstract}
RESUMO - O presente estudo teórico objetiva discorrer sobre as compreensões de Frantz Fanon e Ignacio MartínBaró acerca da relação entre guerra, colonização e saúde mental e como podem contribuir ao entendimento de nossa realidade. Ademais, pretendemos refletir como tais subsídios se aplicam à Psicologia brasileira e seu projeto ético-político. Constatamos uma confluência nas análises dos autores, sobretudo a influência de Fanon para Martín-Baró, orientando-se para uma compreensão da saúde mental remetida ao nosso fazimento colonizado e como este se manifesta, é conformado e intensificado por guerras, mesmo que não formais. Finalmente, traçamos implicações para um projeto de Psicologia que aborde a saúde mental na perspectiva dos autores e, assim, transforme-se, contribuindo para o entendimento e mudança de nossa realidade.
\end{abstract}

PALAVRAS-CHAVE: Frantz Fanon, Ignacio Martín-Baró, guerra, saúde mental, psicologia política

\section{Colonization, War and Mental Health: Fanon, Martín-Baró and the Implications for Brazilian Psychology}

\begin{abstract}
This theoretical article aims to discuss the understandings of Frantz Fanon and Ignacio Martín-Baró about the relationship between war, colonization and mental health and how they can contribute to the understanding of our reality. Furthermore, we intend to reflect on how such subsidies apply to Brazilian Psychology and its ethical-political project. We found a confluence in the authors analyzes, especially Fanon's influence on Martín-Baró, towards an understanding of mental health remitted to our colonized constitution and how it manifests, is shaped and intensified by wars, even if not formal. Finally, we draw implications for a Psychology project that addresses mental health from the authors' perspective and thus transforms itself by contributing to the understanding and change of our reality.
\end{abstract}

KEYWORDS: Frantz Fanon, Ignacio Martín-Baró, war, mental health, political psychology

A saúde mental está, mais do que nunca, em voga. Isso nos indica dois aspectos centrais - igualmente preocupantes -, que se retroalimentam. Primeiro, que estamos sofrendo mais: estudos mostram maior prevalência e incidência de transtornos mentais (Bonadiman et al., 2017). Segundo, que devemos considerar a intensificação de uma lógica de psicopatologização da vida, expressa ilustrativamente nas classificações diagnósticas em saúde mental, como o modelo nosográfico do Código Internacional de Doenças (CID) e Manual de Diagnóstico e Estatística das
Perturbações Mentais (DSM), e que, por sua vez, nos remete às próprias raízes da psiquiatria e seu mandato social de controle e ajustamento. Aliado a isso, temos o lobby de indústrias farmacêuticas, conjugando psicopatologização e medicalização, e de categorias profissionais, para quem quanto mais "loucura", doença e, portanto, loucos e doentes, mais demanda e fontes de renda.

Em suma, vivemos numa lógica de produção de sofrimento. Uma sociabilidade adoecida e que nos adoece, sendo este adoecimento um sintoma ou forma de controle

\footnotetext{
* Apoio: CAPES

** E-mail: phantunes.costa@gmail.com

n Submetido: 14/09/2019; Revisado: 20/12/2019; Aceito: 19/03/2020.
} 
e lucratividade. Esta dinâmica da totalidade, por sua vez, se expressa de maneira diferenciada, de acordo com as particularidades, singularidades e múltiplas mediações que se materializam nos e pelos diferentes contextos, grupos e indivíduos. Por exemplo, Charlson et al. (2019) constataram que $22 \%$ das pessoas de áreas afetadas por guerras e conflitos explícitos no mundo tem transtornos mentais.

Isso nos traz à realidade brasileira. Um país da periferia da dinâmica capitalista, cuja constituição de base colonialescravocrata teve como razão-de-ser a ocupação e rapinagem de bens e gentes para sanar desejos e necessidades mercantiseconômicas dos invasores. Um sentido da colonização e de país "para fora", conforme analisou Caio Prado Júnior (2011). País e suas gentes que se fizeram (e foram feitos) não apenas em contato com o outro, mas a partir dele, com a consequente usurpação e negação de si. Um outro que se desenvolve econômico-politicamente produzindo nosso "subdesenvolvimento" e uma condição de dependência e subserviência econômica, política e sociocultural, com as identidades e subjetividades aqui forjadas expressando tais processos. Nisso, temos o(a) brasileiro(a) colonizado(a) que se fez em terra arrasada; ao invés da somatória entre europeus, indígenas e africanos, é a subtração. Segundo Darcy Ribeiro (2006), um não-europeu também desindigeanizado e desafricanizado. É um ninguém que nasce da ninguendade e, a partir disso, se vê e busca ser algo. E todo esse processo não se deu de maneira harmônica, mas, justamente, nos e pelos entrechoques, tensões e conflitos, internos-externos, objetivos-subjetivos, no que o mesmo Darcy denominou de "estado de guerra latente" (p. 153).

$\mathrm{O}$ que pretendemos, de maneira sintética, é atentar para a necessidade de compreendermos os aspectos conjunturais impregnados por nossas estruturas sociais e história. Uma síntese dialética que nos faça enxergar o passado que se modifica, complexifica e deságua no presente, junto do conjuntural enquanto expressão de um movimento que remete à formação social brasileira. Falar e abordar a saúde mental no Brasil significa considerar a nossa constituição colonizada e como essa se expressa no conflito, na guerra, e por eles. Sendo assim, se os campos do saber-fazer, como a Psicologia, a Psiquiatria e afins, querem compreender e atuar com a saúde mental em nossa atualidade, devem, para além da aparência, entender a forma como vivemos no presente enquanto continuidade de um longo processo histórico - da sociedade e do Brasil circunscrito a ela -, o que nos remete às nossas bases constitutivas. E, nesse movimento, refletir sobre suas próprias fundações teórico-práticas e projetos ético-políticos.

Dois autores da periferia capitalista que trouxeram importantes contribuições para se pensar essa relação entre colonização, guerra e saúde mental foram Frantz Fanon (1925-1961) e Ignacio Martín-Baró (1942-1989). O primeiro foi um psiquiatra, filósofo, intelectual e revolucionário nascido em Martinica, colônia francesa no Caribe, mas com marcante presença na luta pela libertação africana. Já o segundo, foi um padre jesuíta, filósofo, teólogo e psicólogo nascido na Espanha e naturalizado salvadorenho, onde também teve atuação marcante em um contexto de guerra civil pela libertação do povo de El Salvador.

Ambos se propuseram a pensar e transformar a realidade colonial que os circunscrevia e como essa forjava indivíduos por meio da negação, com impactos em suas subjetividades e, portanto, saúde mental. Ademais, foram atravessados por guerras sanguinárias que, pelo lado dos explorados e oprimidos, almejavam autonomia e libertação, e, pelo polo colonizador-imperialista, a manutenção da dominação. No caso de Fanon, isso se deu devido à situação de sua Martinica e, depois, da Argélia, onde decide morar, trabalhar e lutar pela libertação africana da colonização francesa e europeia. Para Martín-Baró, um colonialismo resgatado e atualizado pelo imperialismo dos Estados Unidos da América (EUA) em El Salvador - e América Latina como um todo.

Sobre as várias similitudes entre os dois, que buscaremos apontar ao longo do presente estudo, talvez a mais dolorosa seja a morte de ambos ainda muito jovens. Fanon faleceu com 36 anos, acometido por uma leucemia, e Martín-Baró com 47 anos, assassinado por membros do exército de El Salvador na Universidade Centro Americana (UCA), onde trabalhava (e era vice-reitor), junto de mais cinco companheiros de luta e duas trabalhadoras da universidade.

A partir do exposto, o presente estudo objetiva discorrer sobre as compreensões de Frantz Fanon e Ignacio Martín-Baró acerca da relação entre guerra, colonização e saúde mental e como podem contribuir para a análise e entendimento de nossa situação. Adicionalmente, refletiremos de que forma tais subsídios se estendem e se aplicam à Psicologia brasileira, seu projeto de ser humano e sociedade, na compreensão e abordagem dos fenômenos e realidade do país e suas gentes.

Buscando alcançar o que nos propomos, dividimos o artigo em mais quatro seções. Começaremos por Fanon, com uma breve apresentação sobre a sua trajetória acadêmicomilitante. Depois, focalizaremos nossa análise em seu livro Os Condenados da Terra (Fanon, 2015) e, nele, no capítulo Guerra Colonial e Distúrbios Mentais, extraindo elementos para pensarmos nossa realidade e presente momento histórico. Posteriormente, nos debruçaremos sobre MartínBaró, seguindo o mesmo caminho utilizado com Fanon e enfocando no seu texto Guerra e Saúde Mental (MartínBaró, 2017a). A escolha destas duas obras, complementadas pela análise de outras produções dos autores, se deve ao fato de que nelas, eles se assentam de maneira específica sobre os temas tratados no presente trabalho, por mais que eles atravessem suas trajetórias como um todo.

Dessa forma, acreditamos ser possível apresentar e discorrer sobre como ambos compreendem essa relação entre colonização, guerra e saúde mental e de que formas podem nos ajudar a pensá-la em nossa presente conjuntura. Feito isso, buscaremos alinhavar o pensamento e produções (expressos também em suas militâncias) de Fanon e Martín- 
Baró, extraindo implicações para um projeto de Psicologia brasileiro que considere a importância da colonização, da guerra e da saúde mental em seu cabedal teórico-prático - afinal, também dizem respeito à nossa realidade. Nesse movimento, que tal projeto não só as compreendam, como contribua para as suas respectivas e conjuntas transformações, tomando como horizonte a libertação de nosso povo.

\section{FRANTZ FANON,A GUERRA COLONIAL E OS DISTÚRBIOS MENTAIS}

Ao nascer negro e em uma colônia francesa, Fanon já traz consigo as marcas do colonialismo e da relação dominador-dominado. Apesar de legalmente francês, não o era, pois ser martiniquense e negro significava ser não-francês (não-europeu), e mais, não-humano, pois a universalidade humana nessa relação estava em ser francês/ europeu "puro", sinônimo de branco. Esse estranhamento vai se intensificando conforme amadurece, se tornando mais do que um mero objeto de estudo e prática ao corporificar-se no próprio. Fanon pouco a pouco "se faz" seu objeto de estudo e este, dialeticamente, torna-se sua práxis.

Durante a juventude alista-se no exército francês em decorrência da ascensão do nazismo e, posteriormente, muda-se para a França para estudar, formando-se médicopsiquiatra. Sua vida tomará um rumo radical ao se mudar para a Argélia, em 1953, assumindo a direção de um hospital psiquiátrico e, a partir disso, participando ativamente dos processos revolucionários argelinos e africanos; um movimento de autolibertação do próprio. Nesse processo, agregará subsídios teórico-práticos da psiquiatria, psicanálise, marxismo e existencialismo, formando um caldeirão intelectual-militante. $\mathrm{Na}$ impossibilidade de aprofundarmos mais sua obra e militância, sugerimos os trabalhos de Deivison Faustino, em especial a tese de doutorado "Por que Fanon, Por que agora": Frantz Fanon e os fanonismos no Brasil (2015), em que faz uma densa análise sobre como Fanon é apropriado e debatido no Brasil.

Fanon (2015) conceitua os distúrbios mentais como germes de podridão imperialista/colonial ${ }^{1}$ que deveriam não só serem detectados, mas extirpados, tal como ervas daninhas que empesteiam as terras. Podemos, então, concluir que, se tais germes expressam uma putrefação sistêmica, no horizonte estaria a necessária eliminação deste sistema, e não só as importantes, mas remediativas podas e capinas nos planos objetivo e subjetivo.

Para entender a produção de saúde mental, primeiro deve-se compreender o processo de produção do colonizado, que se dá por meio de sua negação e recusa oriunda do processo de colonização que, por sua vez, é obra do colonizador. Esse colonizador não é um mero indivíduo, mas expressa uma dinâmica de dominação que, no caso de Fanon, por mais que remeta aos meios materiais, aos modos de produção e antagonismos de classe, é centrada na

1 O autor utiliza aqui "imperialismo" (Fanon, 2015, p. 287), enquanto no decorrer do capítulo o termo utilizado é colonialismo. No livro como um todo, Fanon utiliza ambos sem distingui-los, com ênfase no segundo. relação entre nações e continentes, mais especificamente no movimento expansionista europeu de dominação africana. Oriundo dessa ausência, de uma subtração, o colonizado se faz tendo como o espelho o colonizador. Portanto, a não ser que se liberte destes grilhões objetivos e subjetivos, não se enxergará como um ser em si, pois, primeiramente, não se vê e não chegará a ser alguém; mesmo que queira, jamais será o europeu, sinônimo de ser humano. Na melhor das hipóteses, um quase-europeu, logo, um quasehumano. Antes de tudo, um humano que é produzido pela desumanização, um não-humano: “[o] povo colonizado não é apenas um povo dominado. Sob a ocupação alemã, os franceses permaneceram homens. Sob a ocupação francesa, os alemães permaneceram homens" (Fanon, 2015, p. 288).

A colonização compreende uma iniciativa comercial de um país (ou continente) sobre outros, materializada pela ocupação. Orientada para a extração de bens, finca suas raízes na estrutura econômica, remodelando-a às necessidades acumulativas da nação colonizadora e se espraiando pela dinâmica sociocultural, ocupando mentes e corpos e se multideterminando. Nesse cenário, está o argelino, o africano, o ser colonizado e a sua subjetividade colonizada ${ }^{2}$ que se fundem ao próprio ser alienado do modo de produção capitalista. $\mathrm{O}$ sucesso da colonização se dá pela sua capacidade de domar a "natureza insubmissa" (Fanon, 2015 , p. 288). Não por acaso, o crescimento do número de colonizados nos hospitais psiquiátricos expressaria um momento "calmo da colonização" (p. 289). Contudo, considerando as contradições e caráter dialético da realidade, a "pacificação" gera sua própria guerra; um estado constante de conflito, mesmo que apassivado e "pacificamente". Colonização e guerra são indissociáveis.

A guerra analisada por Fanon (2015) é, portanto, uma guerra colonial, que assume, por vezes, "o aspecto de um autêntico genocídio" (p. 290). Se a colonização não assassina de maneira objetiva, fataliza subjetivamente. Cabe pensar que, tanto seus momentos específicos e episódios mais agudos, ao atentarem diretamente contra determinados indivíduos e grupos, poderão desencadear distúrbios mentais, quanto a sua própria essência e atmosfera de apocalipse permanente já é adoecedora. Fazendo aqui uma analogia com a própria medicina, a guerra seria uma "doença crônica", mesmo que com momentos de agudização ou constituída por doenças agudas, sendo que o adoecimento teria sequelas permanentes.

2 Fanon utiliza o termo "personalidade colonizada" (p. 288). 
Fanon (2015) mostra isso quando esquematiza o capítulo supracitado em quatro séries. Na série $A$, ele reúne cinco casos clínicos de argelinos e europeus atendidos por ele que apresentaram transtornos mentais "de tipo reacional" (p. 292), depois de acontecimentos traumáticos e bastante precisos. Na $B$, estão casos e grupos de casos cujo desencadeamento dos distúrbios foi a atmosfera da guerra. A série $C$ aglutina os transtornos pós-tortura (e aqui faz uma importante discussão sobre como a tortura desumaniza o torturado, mas, também o torturador). Por fim, na $D$, estão os distúrbios psicossomáticos de indivíduos internados em campos de concentração, onde a reação sintomática se expressa de maneira mais clara no organismo, no corpo.

Nossa intenção não é focar nesses estudos de caso, até porque o próprio Fanon deixa claro que não se trata de um estudo de psiquiatria, mas uma forma de ilustrar e materializar seus argumentos sobre as implicações subjetivas da colonização via guerra. No início do capítulo, ele, inclusive, alerta para a possibilidade de acharem "inoportunas e singularmente deslocadas" (Fanon, 2015, p. 287) tais inserções. Contudo, no decorrer da leitura e da explicação dos casos, vai ficando clara a justificativa e relevância de tal parte, como forma de ilustrar o que, até então, era explicado e teorizado a partir do real, mesmo que $\mathrm{o}$ autor não fale isso ${ }^{3}$.

Da forma como Fanon (2015) descreve e analisa os casos, as patologias e os distúrbios mentais são, por um lado, sintomas dessa guerra, seja de sua atmosfera e caráter permanente, ou de acontecimentos específicos. Sendo assim, não podem ser entendidos como anomalias, como anormalidades, vide o contexto em que brotam e tendem a expressar. Por outro lado, são também sinalizadores das incongruências destes indivíduos com a realidade em que se encontram circunscritos. Em um ser desumanizado e tolhido de ser tudo aquilo que poderia ser, a subjetividade e o corpo gritam; em um contexto e atmosfera de guerras, tornam-se ensurdecedores. O problema reside nas formas como (não) serão escutados - ao menos como deveriam. Nisso, Fanon empreende uma robusta crítica ao cabedal teórico-prático hegemônico da Psiquiatria e seu caráter ajustador, apassivante, em suma, colonizador. Sendo a Psiquiatria normativa e a colonização a norma, a primeira passaria a ser um dos braços e extensões da segunda.

A própria ideia de cura deve ser refletida, pois, no caso do colonizado, curá-lo, isto é, remetê-lo a padrões anteriores de funcionamento considerados adequados, numa lógica de homeostase, é dar por natural o contexto e focalizar na "desordem" do indivíduo. Além disso, significa almejar sua remissão à condição de não-humano inerente a de colonizado; e, mais, um não-humano dócil e passivo frente à sua própria desumanização. Segundo Fanon (2015): "Disciplinar, domesticar, domar e hoje pacificar são os

3 Vale ressaltar que o livro foi escrito às pressas, pois Fanon lutava contra uma leucemia. O autor faleceu em seis de dezembro de 1961, após ter contato com os primeiros exemplares da obra (Faustino, 2015). vocábulos mais utilizados pelos colonialistas nos territórios ocupados" (p. 350). Não seriam estes os motes e horizontes da Psiquiatria tradicional-hegemônica pelos processos de psicopatologização e medicalização? E da Psicologia Clínica, por meio de lógicas também psicopatologizantes, de ajustamento e controle?

Na esteira da crítica à Psiquiatria, Fanon (2015) demole as teorias "científicas" para quem a composição do cérebro determinaria mecanicamente "a preguiça do indígena, a sua inaptidão intelectual e social e a sua impulsividade quase animal" (p. 350). A isso, chamaremos de estruturalismo (ou determinismo) cerebral e indagamos: não existem correlatos psicológicos? Por exemplo, estruturas rígidas da psiquê, aparelhos psíquicos e personalidades pré-definidos que, se não nascem prontos, se formam logo na idade tenra sem possibilidade posterior de mudança, que também determinariam mecanicamente o que somos e podemos ser. Tratam-se, portanto, de perspectivas anti-humanistas, ao conceberem o ser humano enquanto produto apenas, ser passivo determinado ao longo de sua vida por forças e estruturas as quais não tem incidência e/ou controle.

Partindo das observações fanonianas constatamos que tais explicações não são exclusividade da Psicologia ou Psiquiatria, mas estão presentes, mesmo que por diferentes caminhos, nas ciências como um todo. No caso do Brasil, são muito comuns as teorias que imputam ao brasileiro uma personalidade autoritária per si, ou que traçam sua imagem como preguiçoso, corroborando para a criação de uma autoimagem do corrupto, de um suposto jeitinho brasileiro ${ }^{4}$. Seriam tipos ideais estáticos, prontos, de personalidades dadas e definidoras; interpretações culturalistas, que chegam em um denominador comum às do campo psi supracitadas, mesmo que oriundas da sociologia, antropologia ou ciência política. E aqui vemos que abordar a saúde mental, algo tão em voga em nossa atualidade, com consternações genuínas e bem-intencionadas, significa, antes de tudo, empreender uma ampla reflexão acerca do ser e da realidade aos quais ela constitui e é constituída. Se estes seres e a realidade não se produzem no vácuo, não estão apartados ou são produtos estáticos, o mesmo pode (e deve) ser dito da saúde mental.

Não fazendo este movimento, podemos contribuir para a manutenção do caráter colonizado criticado por Fanon (2015) da Psiquiatria hegemônica, desconsiderando os homens e mulheres como produtos e produtores, que se materializam pela sua própria ação, mesmo que não nas condições desejadas, mas nas fornecidas pela história. Seres, portanto, históricos, que devem ser compreendidos enquanto totalidades múltiplas, dinâmicas e contraditórias inseridas em uma totalidade social que, na particularidade brasileira - tal como a argelina e africana - se fez e faz a partir e pela colonização. Assim, perde-se a oportunidade, inclusive, de entender que possíveis comportamentos -

4 Por exemplo, a interpretação culturalista do antropólogo Roberto DaMatta. 
poderíamos aqui falar da violência, criminalidade, o refúgio à religião etc. -, ao se darem em determinados contextos e períodos históricos e suas condicionalidades, podem se tratar de oposições à ordem que os subjugam e oprimem. Ou seja, a guerra como um mecanismo de perpetuação da colonização, e de maneira contrária e complementar, uma oposição a ela; uma saúde mental adoecida, como sintoma da capacidade da colonização domar o indomável, mas, também, de insubmissões inconscientes destes indivíduos, mesmo que por suas mentes e corpos. Remetendo à observação que Fanon (2015) faz no plano sociológico: “A preguiça do colonizado é a sabotagem consciente da máquina colonial; no plano biológico, é um sistema de autoproteção notável e de qualquer forma é um atraso incontestável para a dominação do ocupante sobre o país global” (p. 340).

Dessa forma, cabe a nós perguntarmos: Em que sentido as teorizações e práticas psi que dizem compreender o real e expressá-lo não partem de determinadas concepções de ser humano e realidade que, por sua vez, são incapazes de englobar todas as possibilidades desse ser e do real? Estariam elas aptas a captar a complexidade humana em seu sentido universal e as particularidades e singularidades que expressam esse todo - e se manifestam nele? Passemos para o outro autor analisado, Ignacio Martín-Baró, que nos dará importantes subsídios para respondê-las.

\section{MARTÍN-BARÓ,A GUERRA E A SAÚDE MENTAL}

A influência de Fanon em Martín-Baró é candente, como poderemos ver a seguir, sobretudo em suas análises sobre a relação entre colonização e violência (Martín-Baró, 2017b, 2017c) e as implicações psicossociais da guerra (Martín-Baró, 2017a). Diferente de Fanon, Martín-Baró sai do país e continente colonizador. E essa inversão não foi simplesmente geográfica, podendo ser compreendida como fruto das próprias preocupações do autor com a realidade latino-americana.

Em El Salvador, Martín-Baró se forma em Psicologia (1975), após já ter concluído os cursos de Filosofia e Teologia. Ao longo dos anos 1970 e 1980 vai adensando seu arcabouço teórico-prático, desde incorporações iniciais e utilizações acríticas de modelos e teorias vindas de fora, sobretudo, do cabedal psicológico e psicanalítico, até movimentos posteriores de crítica e formulação de um projeto de Psicologia “contra a ordem", em prol da produção de um novo mundo (Lacerda Júnior, 2017, p. 15) ${ }^{5}$. Nisso, a influência de Fanon se faz presente junto a de outros referenciais críticos da própria Psicologia, inspirações marxistas, dentre outros.

Dado o seu realismo crítico, que significava um movimento da e para a realidade no intuito de transformála, era corriqueiro Martín-Baró começar seus textos ou intervenções com uma análise da conjuntura salvadorenha e, em determinado nível, latino-americana. Em O Papel do Psicólogo, não fugindo à regra, ele esboça uma caracterização dessa situação, a partir de três pontos principais ${ }^{6}$ : (a) a condição de profunda injustiça estrutural; (b) as guerras revolucionárias ou situações de quase-guerra;

5 Sobre a divulgação do pensamento de Martín-Baró no Brasil, são relevantes os esforços de Yayá Andrade, José Pinheiro e Oswaldo Yamamoto, Raquel Guzzo e, sobretudo, de Fernando Lacerda Júnior, tendo na coletânea Crítica e Libertação na Psicologia: Estudos Psicossociais (Lacerda Júnior, 2017), sua máxima expressão até o momento, com 14 textos traduzidos para o português brasileiro.

6 Em outros textos do autor, apesar de pequenas diferenças, os pontos elencados são os mesmos ou se assemelham. e (c) o imperialismo estadunidense atingindo a soberania nacional e transformando as nações em seus satélites (Martín-Baró, 1996).

É nessa conjuntura, vinculada ao seu processo histórico e formativo, que o autor procurará analisar as relações entre a constituição colonizada e, posteriormente, de imperialismo estadunidense, com a situação de guerra e implicações para a saúde mental. Para realizar essa empreitada, parte da concepção de saúde mental como a "materialização, na pessoa ou no grupo, do caráter humanizador ou alienante de uma estrutura de relações históricas" (Martín-Baró, 2017a, p. 251). Dessa forma, contrapõe compreensões, segundo o próprio, muito pobres sobre a saúde mental, que vão desde a ausência de transtornos psíquicos até o pleno e homeostático funcionamento psicológico. Com isso, também critica noções de que saúde mental seria uma expressão interna individual e individualizada, produzida no vazio histórico. A própria separação entre saúde e saúde mental, nos indica uma tendência a compreensões reducionistas e cartesianas: predominantemente organicista, no caso da primeira, e psicologizante no da segunda, como se físico e mente estivessem apartados, bem como o individual do social. Adicionalmente, em $O$ Psicólogo no Processo Revolucionário, escreverá que a "distribuição da saúde mental está vinculada com a distribuição da riqueza produzida" (Martín-Baró, 2017d, p. 29), aproximando-se de uma apreensão materialista histórico-dialética.

A guerra, para Martín-Baró, deve ser entendida por aquilo que conforma e altera na dinâmica social, tendo três vetores que se retroalimentam: (a) violência; (b) polarização social e (c) mentira (Martín-Baró, 2017a). Sobre a primeira, não se pode compreendê-la como comportamento individual, fruto de mecanismos psíquicos (auto)destrutivos, mas inerente ao capitalismo, tendo um caráter estrutural. Remetendo a Fanon, "a violência imposta pelo colonizador é introjetada pelo colonizado, ficando ancorada em sua musculatura como uma tensão reprimida e em sua mente como culpa assumida" (Martín-Baró, 2017b, p. 193). Por conta disso, a 
violência perpetrada contra os explorados e oprimidos deve ser diferenciada da que estes produzem quando se voltam contra a ordem, isto é, a violência revolucionária, que passa a possuir um papel humanizador (Martins \& Lacerda Júnior, 2014). Ademais, se com o prolongamento da guerra temos a normalização da violência, ao invés de uma anomalia, poderíamos pensar se a naturalização e o caráter sistêmico da violência já não configurariam um contexto de guerra, mesmo que não formalmente. Para Martín-Baró, pelo menos, já seria uma condição.

A polarização social seria "o deslocamento dos grupos para extremos opostos" (Martín-Baró, 2017a, p. 257). É formada uma fratura diferenciativa no tecido social entre nós e eles, produzindo inimigos internos culpabilizados pelas condições de vida. Acentuadas as diferenças, elas se ampliam para todos setores da população e perfazem a dinâmica social como um todo.

Já a mentira fornece os ingredientes que estavam faltando para esse caldeirão efervescente. Forja-se uma realidade onde a única verdade é a de que se "trata de um mundo falso" (p. 259), de modo que a violência se torna a solução para si própria. A partir dessa dinâmica, as implicações da guerra para a saúde mental devem ser pensadas segundo MartínBaró (2017a), considerando os antagonismos de classe, os próprios envolvimentos nos conflitos e a temporalidade de seu desenrolar, isto é, a sua cronicidade.

Miremos a nossa conjuntura e a sua formação. Em nosso caso, os antagonismos sociais são mistificados e se "transferem" aos indivíduos, no sentido que as fraturas sociais de classes, que se consubstanciam às de raça e etnia, gênero e sexualidade, que são estruturais, se "individualizam", ocasionando essa polarização e disputa entre grupos e indivíduos. Nisso, tais fraturas estruturantes, são mistificadas, obnubiladas, se mantendo. A polarização, que emerge da condição desigual de nossa sociabilidade, se individualiza, "encarna" nos indivíduos - muitos deles também explorados e oprimidos -, fazendo com que se polarizem e disputem entre si, enquanto a ordem permanece intacta ou se aproveita disso para intensificar sua condição de desigualdade.

E o que dizer das ditas fake news, da sensação de descrença e descrédito de legitimidade no regime político, eivado de denúncias de corrupção, se não elementos constituintes dessa realidade "mentirosa". Entretanto, se um sistema necessita se pautar por inversões e mistificações a partir da mentira, não seria ele mesmo uma mentira? Ademais, não seria a própria máxima de que políticos são todos corruptos, logo a política é ruim, também uma mentira proposital para a deslegitimação de tal âmbito, contribuindo para a perpetuação deste sistema, novamente, mentiroso?

A partir disso, não teríamos todos os elementos necessários para a caracterização de uma guerra, segundo Martín-Baró, por mais que não estejamos em uma formalmente, seja ela civil ou contra outras nações? Mesmo a resposta à pergunta sendo negativa, não se invalida as contribuições baronianas, pois como destacaram Martins e Lacerda Júnior (2014), a partir da análise das produções do autor sobre a violência, "o diferencial da guerra parece ser não o surgimento de novos processos, mas a intensificação de práticas bárbaras já existentes no cotidiano" (p. 585).

A questão imperante passa a ser como romper com esse estado das coisas e sociabilidade altamente eficazes em se manter, a despeito de si próprios. Nisso a dimensão subjetiva possui um papel de relevo, como ambos autores sinalizam. Sabemos da violência e ela nos atravessa, só que personalizada no outro. Consequentemente, nos polarizamos, como se a condição sistêmica de violência intrínseca e estrutural da sociabilidade capitalista e, sobretudo, a de constituição colonizada fosse culpa desses outros, com estes, em grande parte, sendo também as principais vítimas dessa ordem violenta, isto é, os explorados e oprimidos. Os níveis de encarceramento em massa não nos deixam mentir, fazendo da população encarcerada do Brasil a terceira maior no mundo ${ }^{7}$, mas com intensificação da violência, vide os dados que apresentaremos a seguir. Por fim, as próprias formas de se apreender tal dinâmica em sua complexidade podem também conformar "mentiras", no sentido que a descaracterizam e obnubilizam, tal como Fanon apontou para os engendramentos e o papel desempenhado pela Psiquiatria em contextos de colonização.

Considerando todos estes elementos, não podemos dissociar a saúde mental da ordem social e como essa se forma historicamente, vinculada ao próprio movimento da sociedade. Segundo Martín-Baró (2017a),

se a base da saúde mental de um povo encontra-se na existência de relações humanizadoras, de vínculos coletivos nos quais e pelos quais se afirma a humanidade pessoal de cada um e não se nega a realidade de ninguém, então a construção de uma sociedade nova ou, pelo menos, melhor e mais justa, não é somente um problema econômico e político; é também, e por princípio, um problema de saúde mental. (p. 267)

Tomando esses princípios e transformando-os em horizontes, é possível à Psicologia brasileira contribuir para a compreensão e abordagem da saúde mental, vinculadas a um projeto de transformação societária radical. Contudo, esbarramos em limitações não só do contexto latinoamericano que se plasmam aos obstáculos e contradições da totalidade social, bem como da própria Psicologia enquanto produto e conformadora dessa realidade e sua dinâmica. No texto Para uma Psicologia da Libertação, o autor indaga:

Como é possível que nós, psicólogos latino-americanos, não tenhamos sido capazes de descobrir todo esse rico potencial de virtudes de nossos povos e, consciente ou inconscientemente,

7 Segundo o Banco Nacional de Monitoramento de Presos, em 17 de julho de 2019, 812.564 pessoas estavam encarceradas no país. Fonte: https://www.cnj.jus.br/sistema-carcerario-e-execucao-penal/cadastronacional-de-presos-bnmp-2-0 
dirigimos nossos olhos para outros países e para outras culturas na hora de definir objetivos e ideais? (Martín-Baró, 2011, p. 196)

Trata-se de uma provocação proposital, afinal o mesmo só a faz depois de respondê-la. E a resposta estaria no que o próprio denominou de "escravidão" ou "miséria" da psicologia latino-americana, que "tem suas raízes em uma história de dependência colonial” (Martín-Baró, 2011). Ora, se não é a própria psicologia latino-americana como produção colonizada: não por ter suas bases oriundas de fora, mas porque estas se assentam em e/ou expressam concepções de indivíduo e sociedade que não necessariamente as nossas ou nos tomam de maneira inferiorizada, subordinada; um ser e realidade proeminentemente europeus e estadunidenses, levados à condição de universais. Portanto, tal colonização, que pode ser entendida a partir de suas bases materiais de dominação, também irá se propagar nas ideias, nas teorias e, logo, na Psicologia -, adentrando nas mentes e encarnando nos corpos, ao passo que por eles também se sustentará, retornando e não mais se dissociando desse chão do real.

\section{PSICOLOGIA LIBERTADORA, LIBERTAÇÃO DA PSICOLOGIA BRASILEIRA}

Guerra, saúde mental em contextos de colonização e imperialismo. Eis o todo temático que nos propusemos presunçosamente a perscrutar a partir dos autores supracitados. Engendramentos e expressões do movimento e da dinâmica de uma totalidade - a nossa sociedade -, particularizada em nossas condições colonizadas, e singularizada nos homens e mulheres. Implicações para se (re)pensar a Psicologia enquanto todo que também se faz em meio a essa totalidade, e, portanto, a expressa, juntamente de suas contradições. Sabemos que Argélia, El Salvador e Brasil são diferentes, assim como os momentos históricos analisados pelos autores. Mas uma das coisas que nos uniria na diversidade seria esse nosso fazimento colonizado e como este se manifesta e é conformado e intensificado por guerras, mesmo que não formais ou nomeadas dessa forma. Ao nos fazermos (e nos fazerem) nisso e por isso, trazemos até hoje chagas e feridas abertas, amalgamadas a estruturas antagônicas que se complexificam e dinamizam no próprio movimento sócio histórico.

Assim, como pensar um projeto de Psicologia que tome essa realidade como parâmetro e se volte para ela, contribuindo para sua transformação? Na presente seção, buscaremos apresentar não uma solução pronta e fechada, mas alguns indicativos de resposta. Cabe apenas ressaltar que, ao contrário de Martín-Baró, psicólogo de formação e atuação, Fanon, enquanto psiquiatra, não buscou desenvolver um projeto de Psicologia em si. Entretanto, por compor o campo psi, abordando temas afeitos e centrais à Psicologia, e devido à realidade em que se encontrava e às similitudes com as esquematizações e proposições baronianas que bebem na sua fonte, tal exercício se mostra coerente.

De acordo com as definições e observações de MartínBaró e Fanon, questionamos se, de fato, não vivemos em guerra. Além do mais, qual guerra em nosso movimento histórico não foi colonial ou imperialista. Mesmo as internas não tiveram um objetivo de dominação e, no fim, supressão objetiva-subjetiva daqueles para os quais se voltaram? Peguemos, por exemplo, dados da realidade brasileira. Segundo o Atlas da Violência 2019, foram 65.602 homicídios no Brasil em 2017, uma taxa de 31,6 a cada 100 mil habitantes, representando o maior número da história. Desse total de vítimas, 75,5\% eram negros(as), sendo que para cada vítima de homicídio não negra, 2,7 negros(as) morreram. De 2007 a 2017 a taxa de homicídios de negros(as) cresceu 33,1\% (Instituto de Pesquisa Econômica Aplicada \& Fórum Brasileiro de Segurança Pública [IPEA], 2019). No mesmo 2017, 5.159 homicídios foram registrados em decorrência de intervenções policiais (média de 14 por dia), representando um crescimento de $21 \%$ (Fórum Brasileiro de Segurança Pública, 2018). E sabemos que tal número é subestimado, devido à fonte. O que é isso se não um cenário explícito de guerra, um "autêntico genocídio" nas palavras de Fanon (2015, p. 290) perpetrado, antes de tudo, pelo próprio Estado? Um terrorismo de Estado como observou Martín-Baró para El Salvador em guerra civil. Paremos apenas para conjecturar sobre os impactos subjetivos dessa realidade, conformados pelo nosso próprio histórico de formação social circunscritos à totalidade.

A mola-mestra desse genocídio é a denominada "Guerra às Drogas" (IPEA, 2019). Não obstante, tal "guerra" foi orquestrada em um plano mundial, entre outros motivos, como forma de justificar ação imperialista dos Estados Unidos, sobretudo na América Latina, imputando aos países latino-americanos a pecha de produtores das drogas que adentram em terras estadunidenses, vitimizando sua população "indefesa". No plano interno brasileiro, tal "guerra", na verdade, não se volta para as coisas - assim como nenhuma guerra -, mas para pessoas. E estas pessoas, conforme os dados demonstram, são, justamente, aquelas historicamente mais pauperizadas, compondo o grosso da classe trabalhadora que se consubstancia no racismo estrutural e, não por acaso, é marginalizada territorialmente. Temos, portanto, os alvos de tal "guerra" pretos(as), pobres e periféricos(as), numa lógica que visa e fomenta o seu genocídio e extermínio objetivo-subjetivo. Ou seja, um novo que se funda no velho e o arrasta consigo; e um velho que puxa o novo pelos cabelos e o impede de ser inteiramente novo.

Como Fanon (2015) demonstrou, não há possibilidade de passarmos ilesos por essa onda, essa atmosfera que 
respinga e cheira a sangue. Mesmo que alguns de nós não sejam os alvos prioritários dessa "guerra" ou aqueles que apertarão seus gatilhos atentando contra semelhantes, todos nós nos desumanizamos - obviamente que de maneiras diferentes. Em uma sociabilidade que se pauta, justamente, pela desumanização do ser humano, ao mercantilizá-lo junto de suas necessidades, o que dizer quando esta se produz amalgamada à colonização, de base escravocrata, que subtraiu, animalizou, aninguenzou. Conforme o próprio diz em Em Defesa da Revolução Africana, "o Norte-Africano apresenta-se mergulhado no vago" (Fanon, 1980, p. 8), e, de maneira mais elaborada,

Ameaçado na sua cidadania, o Norte-Africano reúne todas as condições que tornam um homem doente. Sem família, sem amor, sem relações humanas, sem comunhão com a coletividade, o primeiro encontro consigo próprio far-se-á de um modo neurótico, de um modo patológico, sentir-se-á esgotado, sem vida, em corpo a corpo com a morte, uma morte aquém da morte, uma morte na vida. (Fanon, 1980, p. 17)

Conforme introdução, os dados sobre transtornos mentais, suicídio e seus crescimentos corroboram o autor. Não à toa, como diz Fanon (2015), a colonização é uma "grande provedora dos hospitais psiquiátricos" (p. 287). Não só a colonização, mas o capitalismo, sobretudo a partir de sua fase monopólica e o consequente movimento imperialista a partir do final do século XIX, demonstrando sua plena normalidade ao produzir doenças, violência e criminalidade, encher manicômios e prisões - e ainda lucrar com isso. Ao que Fanon (1980) aponta acerca da "síndroma do norte-africano" (p. 7), da formação do ser colonizado, podemos fundi-la à conclusão marxiana acerca do trabalho alienado na sociabilidade capitalista, onde "o homem (o trabalhador) só se sente livremente ativo em suas funções animais [...] enquanto que em suas funções humanas se reduz a um animal. $\mathrm{O}$ animal se torna humano e o humano se torna animal" (Marx, 2004, p. 83). Nesse sentido, o movimento de humanização desumanizante do modo de produção capitalista se plasma ao da colonização, com a produção reificada de um todo coeso ainda mais animalizante.

Com base nisso, uma importante ressalva a ser feita diz respeito aos contextos de guerra de Fanon e MartínBaró, com movimentos intentando romper com as condições materiais de opressão e exploração, mesmo que violentamente reprimidos e derrotados. No Brasil presente cabe a nós analisarmos em que sentido nossas "guerras" se voltam não para a supressão, mas à manutenção da ordem e intensificação de seu caráter desumanizador. Ou seja, não se trata de guerras onde a libertação, fim da dominação etc. estão em disputa. Não são constituídas por movimentos com capacidade (e, em alguns casos, intencionalidade) de colocar em xeque o sistema e suas estruturas, fazendo com que a polarização, conforme Martín-Baró, se engendre entre Estado e determinadas parcelas historicamente subalternizadas, e entre os próprios indivíduos, boa parte deles explorados e oprimidos, e não entre dominados e dominadores, explorados e exploradores.

Outro ponto importante diz respeito à relação colonização-imperialismo. Fanon $(1980 ; 2015)$ centraliza sua interpretação na condição colonizada do(a) africano(a), algo que não deixou de existir, pelo contrário, diz do erigir e se desenvolver capitalista. Isso se deve à própria situação da Argélia, que na época ainda era uma colônia (sua Guerra de Independência termina em 1962, com a proclamação da República Popular Democrática da Argélia). Já Martín-Baró $(1996,2011,2017 \mathrm{a}, 2017 \mathrm{c}, 2017 \mathrm{~d})$ se volta ao imperialismo para se retratar à realidade salvadorenha, não mais colônia, mas não menos subordinada aos EUA. Contudo, nenhum dos dois defende a tese de que a libertação do(a) africano(a) e salvadorenho(a) virá "apenas" pela sua libertação da França/ Europa e EUA que os exploram e oprimem. Até porque tal exploração é, antes de tudo, estrutural e estruturante no modo de produção e sociabilidade capitalista, isto é, do capital, que se assentou e se utilizou do colonialismo e tem no imperialismo mecanismos para se desenvolver e perpetuar, naturalizando-se nesse processo. Há uma continuidade da condição colonial numa etapa de desenvolvimento posterior - imperialista - da sociedade capitalista; uma preservação reengendrada e dinamizada, formando um "novo-velho". Logo, o horizonte libertador, explicitado por ambos, não se dará "apenas" por uma revolução nacional, mas uma revolução socialista internacional; a libertação do conjunto dos explorados e oprimidos daquilo e aqueles que lhes exploram e oprimem. A construção de um novo ser humano, liberto, se dará quando este se libertar de todos os grilhões societários que o aprisionam, sendo este um trabalho que engloba todos e todas, inclusive dos países colonizadores e imperialistas.

O Terceiro Mundo não pretende organizar uma imensa cruzada da fome contra toda a Europa. O que ele espera daqueles que o mantiveram na escravidão durante séculos, é que o ajudem a reabilitar o homem, a fazer com que o homem triunfe por toda a parte, de uma vez por todas. (Fanon, 2015, p. 126)

Tal movimento não se dará por uma súbita conscientização e sentimento de culpa do polo dominador acerca das "maldades" impetradas. Não se trata de uma discussão centralizada na moralidade. Ele será forjado pelo dominado em seu processo de libertar-se.

A partir dessa realidade, como pensar e abordar as subjetividades dos(as) brasileiros(as)? Ou melhor, dada a impossibilidade de esgotamento das respostas possíveis: como fazer isso desatrelando-as de nossa formação colonizada-escravocrata e posterior condição de dependência e subserviência na sociabilidade capitalista imperialista? A partir dos autores e da própria análise da realidade brasileira, isso é impossível. Mesmo não considerando tais engendramentos, eles estão presentes nestas subjetividades. O que fazer, portanto? 
Primeiramente, voltando-nos para as maiorias populares, cabe concebê-los enquanto classe trabalhadora e, por isso, alienados(as) e desumanizado(as), em um país da periferia subordinado e dependente, inserido tardiamente na ordem mundial capitalista e divisão internacional do trabalho. Um país cujo "subdesenvolvimento" se deu no e pelo desenvolvimento colonialista e, posteriormente, imperialista, dos ditos países desenvolvidos, e um ser que se produz em meio a isso, a partir da ausência, da subtração, sendo negado. Uma dependência - não implicando aqui em uma natureza inferiorizada - que é, antes de tudo, econômica e política, mas também cultural e, portanto, subjetiva, formando um todo maior que a soma das partes e que se move conjuntamente. Por isso, que também se aloja em nossas "mentes" e se sustenta a partir delas.

Seguindo na esteira de reflexão de Fanon (2008) em Pele negra, máscaras brancas, como pensar e tratar da "experiência vivida do negro" (p. 103), do "preto e a psicopatologia" (p. 127), que habita uma "zona de nãoser" (p. 26), sem considerar que nos fazemos no e pelo racismo estrutural. Racismo que nos remete à colonização escravocrata que nele se engendra e dele se utiliza, fazendo com que tal desumanização seja ainda mais "desumanizante". Na colonização, enquanto movimento mercantil-empresarial, temos o branco (europeu) dominador elevado ao padrão universal, com o conceito de raça sendo criado e servindo como justificador da dominação decorrente desse processo. Consequentemente, o(a) negro(a) passa não apenas a ser inferiorizado, mas considerado um(a) nãohumano(a), pois não é branco(a), tendo como implicação subjetiva principal o assujeitamento e negação de si, das origens etc. Nessa esteira, aspectos socioculturais vinculados ao ser "branco" também se universalizam, enquanto outros são apagados, silenciados, aculturados ou incorporados, de acordo com os desígnios interesses dominantes, a partir de uma branquitude também forjada como idealização. De acordo com o autor, "uma sociedade é racista ou não o é" (p. 85) e a nossa é, não importando se "menos" ou "mais" que outra, que em determinada região, estado, município ou momento histórico. Se este racismo é estrutural, a anomalia, isto é, a anormalidade é o não-racismo (Almeida, 2018). A própria tentativa de hierarquização e de minimização já significam a aceitação de algo que é inaceitável: o racismo. Ele deve ser combatido e expurgado; não deve existir.

Poderíamos expandir tais reflexões, guardadas as devidas proporções e especificidades - as quais não temos espaço para escrutinar - para a condição da mulher, e Fanon (2008) faz isso ao longo de sua vida, aliás, com capítulos específicos em Pele negra, máscaras brancas, ao discutir sobre a "[a] mulher de cor e o branco" (p. 53), "[o] homem de cor e a branca" (p. 69), indicando a indissociabilidade e consubstancialidade entre classe, raça e gênero; entre exploração e opressões. No caso brasileiro, inclusive, o conceito de raça, se utilizado de maneira isolada, sem dialogar e/ou incorporar a esfera e dimensão étnica também se mostra insuficiente, desconsiderando nossos povos originários e sua diversidade. Cabe ressaltar também as produções de Martín-Baró sobre o machismo e a condição da mulher salvadorenha (só para citar um exemplo, MartínBaró, 1990).

É possível continuar com esse movimento, mas acreditamos já termos deixado claro nossos argumentos - e os dos autores em que nos fundamentamos. Apenas citaremos alguns panoramas captados pela literatura acadêmica. Por exemplo, as prevalências de transtornos mentais e índices de suicídio são maiores na população negra, em comparação com a branca (Ministério da Saúde, 2018; Smolen \& Araújo, 2017), assim como nas mulheres quando comparadas aos homens (Gonçalves et al., 2014). Em ambos os casos, existem associações com fatores socioeconômicos, como desemprego, baixa escolaridade e renda. Com isso, gostaríamos, inclusive, de levantar um olhar crítico sobre as concepções comuns na própria academia sobre classe, gênero, raça, etnia, dentre outros, tratados de maneira individualizada e/ou como variáveis (ou reduzidas a elas), recortes, como se fossem elementos em si restritos à quantificação, e não como partes da totalidade social, devendo ser compreendidos circunscritos a ela, e que se produzem em consubstancialidade. Sobre o último, isso não significa que suas especificidades devem ser desconsideradas, mas que devemos refletir sobre como têm sido abordadas e compreendidas.

Remetendo de maneira mais enfática à Psicologia, gostaríamos apenas de indagar como é possível, por exemplo, uma clínica à mulher, sem considerar sua formação objetiva-subjetiva e as produções de identidades, numa sociedade que se estrutura no e pelo patriarcado e machismo? Da mesma forma, um(a) negro(a), o racismo estrutural e a branquitude como ideal de ser - introjetada, inclusive, por ele(a)? Complementarmente, um homem, um(a) branco(a)? E outras populações subalternizadas como a LGBT+? Por fim, e atravessando todos(as) estes(as), um(a) trabalhador(a) que, ao vender sua força de trabalho, é explorado(a) e alienado(a) do que produz, do próprio trabalho, dos outros e de si mesmo?

Separamos estes exemplos, bem como as estruturas que expressam, para sermos didáticos, pois sabemos e mencionamos acima que a realidade não se dá de maneira recortada, parcializada. Tais fragmentações são abstrações que fazemos para melhor compreender suas mediações e especificidades, mas que devem ser "reinseridas" no todo, que é onde se formam, produzindo essa totalidade múltipla e dinâmica que, por sua vez, é mais que a soma das partes. Ou seja, como tratar qualquer ser humano, desconsiderando seu fazimento na conjunção de um antagonismo de classes, raças, etnias, gêneros e sexualidade? E tudo isso anabolizado na guerra e violência.

Escaldados pela "miséria" e "escravidão" da Psicologia latino-americana (Martín-Baró, 2011), sabemos que é possível desconsiderar estes elementos, porque a Psicologia 
o fez e faz, o que, no fim, significa descaracterizar o seu próprio "objeto" de estudo e intervenção - o ser humano e sua realidade (Costa; Lordello, 2019). Sendo assim, reformularemos nossa indagação: como ousa a Psicologia, em especial a nossa, dizer tratar e cuidar do ser humano em suas particularidades e singularidades latino-americanas e brasileiras? Aqui focalizamos na clínica, mas isso se expande para outros campos e especialidades: na educação, avaliação psicológica, psicologia social etc., afinal seus “objetos” de estudo e intervenção são estes mesmos seres e realidade. Remetendo-nos, novamente, a Martín-Baró (1996) e o seu O papel do psicólogo (e aqui é importante atentar que ele se refere à categoria "psicólogo" e não apenas a determinadas especialidades), nossas perguntas e respostas

não devem centrar-se tanto no onde, mas no a partir de quem; não tanto em como se está realizando algo, quanto em beneficio de quem; e, assim, não tanto sobre o tipo de atividade que se pratica (clínica, escolar, industrial, comunitária ou outra), mas sobre quais são as consequências históricas concretas que essa atividade está produzindo. (p. 22)

Caso o nosso propósito seja contribuir para libertação de nossos povos, tal como os de Martín-Baró e Frantz Fanon, ajudando a edificar um novo ser, devemos nos deparar com uma indigesta, mas real e imprescindível constatação: não conseguiremos isso pela Psicologia em si. Primeiro, em decorrência do fato de que a Psicologia enquanto complexo do saber-fazer particular não é capaz de compreender nem aquilo que ela se propõe, seja ela a subjetividade, a mente, a psique, o comportamento, que, não importando as diferenças, remetem ao ser humano. Fanon e Martín-Baró demonstram isso claramente a partir da necessidade de articulação no plano abstrato-teórico e no concreto, da ação política, com outros complexos teórico-práticos.

Em segundo lugar, se os homens e mulheres libertos são os "donos de todos os meios materiais que tornam possível a transformação radical da sociedade" (Fanon, 2015, p. 357), transformar radicalmente a sociedade é esse apoderamento por eles(as) dos meios materiais; das condições concretas para produção e reprodução da vida e, portanto, de si próprios. Tal constatação nos remete à vinculação baroniana entre alienação mental e a riqueza socialmente produzida, e não só a essa riqueza, mas aos meios que as produzem que se encontram apropriados por poucos - assim como as riquezas produzidas. E esse processo se chama revolução, como o mesmo apregoa: "A questão é que talvez os indivíduos não precisem de tratamento, mas a sociedade. E o tratamento da sociedade se chama revolução" (Martín-Baró 1973, p. 204).

Contudo, o que fazer enquanto tal revolução não vem? Ou, melhor, como contribuir com ela, entendendo-a como processualidade e a possibilidade pela qual, na produção de saúde mental, a humanização não só predomine frente à desumanização, mas a suprima? Seguindo as trilhas do próprio autor nas reflexões sobre o papel do psicólogo no processo revolucionário:
O psicólogo terá que antecipar os problemas que surgirão com a finalidade de facilitar e humanizar a passagem à nova sociedade. No curto prazo, terá que atender os 'traumas' do conflito e da desintegração social. A médio e longo prazos, deverá colaborar na edificação social de um homem novo, baseado em necessidades menos individualistas e em objetivos que partem da justa solidariedade. (Martín-Baró, 2017d, p. 26)

Ambos seguem fornecendo subsídios para essa empreitada, sobretudo, pelo processo de intentar devolver humanidade a esse povo, humanizando a si mesmo e, nisso, remontando "os caminhos da história" (Fanon, 2015, p. 339). Os problemas teóricos deverão ser modificados, possibilitando "explicar sempre, a toda hora e em todo lugar, desmistificar, perseguir esse insulto ao homem" (p. 351) e ajudando a tomada de consciência. A revolução progride não apenas nos campos de batalha, na disputa política e militância, mas avançando simultaneamente nas consciências. Enquanto psicólogos(as), por mais que não sejamos capazes de chafurdar e transformar as estruturas sociais, bem como modificar nossa história e sanar a(s) guerra(s), trabalhamos com homens e mulheres não apenas produtos, mas produtores desta realidade e de si mesmos, sendo, portanto, os únicos capazes de suplantá-la, produzindo-se novos ao criarem o novo.

De maneira bastante semelhante à Fanon, e de modo esquemático, Martín-Baró (2011), irá propor três tarefas urgentes à Psicologia latino-americana: (a) recuperar a memória histórica; (b) desideologizar o senso comum e a experiência cotidiana; e (c) potencializar as virtudes das maiorias populares, as quais nossa práxis deve estar comprometida. Ao longo de sua obra, o autor irá reiterálas (p. ex., Martín-Baró, 1996, 2017b, 2017c). Apesar de enfatizar, em alguns momentos, uma ao invés das outras, não significará uma alteração no sentido de seu projeto $p s i$ que é a libertação dessa maiorias populares latino-americanas exploradas e oprimidas.

Os próprios autores demonstraram isso com suas práticas enquanto psicólogo e psiquiatra, politizando suas tecnicidades e orientando-as para as maiorias populares. E, novamente, seus exemplos devem valer para qualquer psicólogo(a): clínico(a), escolar-educacional, comunitário(a), etc. Fanon fez isso modificando a estrutura e lógica de funcionamento do hospital em que trabalhou (Faustino, 2015) e os próprios exemplos que compõem o último capítulo de Os Condenados da Terra, demonstram tal movimento. Contudo, não se contentou "apenas" com isso, militando pela libertação argelina e africana. Martín-Baró idem, não como clínico, mas no que poderíamos caracterizar hoje como um psicólogo sociocomunitário e militante político. Ambos enquanto técnicos-trabalhadores (seja na psiquiatra ou psicologia e trabalhos administrativos), pesquisadores-acadêmicos e intelectuais (e, nisso, filósofos, sociólogos, teólogos etc., rompendo com as especializações do conhecimento) e militantes revolucionários, anticolonialistas e antiimperialistas. Com isso, não é pretendido decretar uma 
compulsoriedade militante e/ou revolucionária, apenas demonstrar a partir de Martín-Baró e Fanon, nas maneiras singulares de cada, que se o horizonte é acabar com a guerra, a colonização, imperialismo e produzir humanização, saúde e saúde mental, em suma, contribuir para a libertação, é necessário modificarmos a Psicologia e o campo psi, mas irmos para além dele.

Finalizando, a partir de Ignácio Martín-Baró e Frantz Fanon, explicitamos que existem possibilidades de a
Psicologia - e seu quefazer - conformar um projeto éticopolítico voltado para as maiorias populares brasileiras exploradas e oprimidas, orientando-se pela sua libertação. Mesmo que seja tímido e limitado frente ao tamanho do desafio que temos enquanto sociedade, de forma alguma é insignificante. Entretanto, se concordamos com a premência de uma Psicologia da Libertação, construí-la "requer uma libertação prévia da Psicologia” (Martín-Baró, 2011, p. 196).

\section{CONSIDERAÇÕES FINAIS}

No presente estudo discorremos sobre o pensamento de Frantz Fanon e Ignacio Martín-Baró acerca da relação entre guerra, colonização e saúde mental e como tais "temas", na forma como são compreendidos pelos autores, tornam-se ainda mais prementes na atual conjuntura brasileira. Constatamos uma confluência nas análises dos autores, sobretudo a influência de Fanon para Martín-Baró. Como consequência, traçamos algumas implicações para um projeto de Psicologia que aborde a saúde mental na perspectiva dos autores e, assim, transforme-se contribuindo para o entendimento e mudança de nossa conjuntura em sua historicidade.

Gostaríamos de finalizar o presente estudo ressaltando as próprias trajetórias de vida de Ignácio Martín-Baró e Frantz
Fanon, que nos apontam possibilidades e um horizonte mais do que possível: necessário. Em ambos os casos, práxis como critérios de verdade no sentido mais freireano possível, onde, de fato, não houve distância entre o que se fez e o que se falou. Nos casos dos autores aqui trabalhados, as ideias não ficaram restritas ao papel, mas tornaram-se seus atos, corporificaram-se em pés e mãos. $\mathrm{E}$ ambos, ao se fazerem por suas ações, tornaram-se suas ideias. Praticaram o que disseram e, nisso, fizeram-se e o foram. Ficam os desafios para psicólogos(as), mas, mais do que isso, as inspirações como seres humanos, que só poderão ser libertos quando não houver mais nenhum outro explorado e oprimido: física e subjetivamente.

\section{REFERÊNCIAS}

Almeida, S. (2018). O que é racismo estrutural? Letramento.

Bonadiman, C. S. C., Passos, V. M. A., Mooney, M., Naghavi, M., \& Melo, A. P. S. (2017). A carga dos transtornos mentais e decorrentes do uso de substâncias psicoativas no Brasil: Estudo de Carga Global de Doença, 1990 e 2015. Revista Brasileira de Epidemiologia, 20(Suppl. 1), 191-204. https:// doi.org/10.1590/1980-5497201700050016

Charlson, F., Ommeren, M., Flaxman, A., Cornett, J. Whiteford, H., \& Saxena, S. (2019). New WHO prevalence estimates of mental disorders in conflict settings: A systematic review and meta-analysis. Lancet, 394, 240-248. https://doi.org/10.1016/ S0140-6736(19)30934-1

Costa, P. H. A., \& Lordello, S. R. (2019). Psicologia e realidade brasileira: Notas preliminares para uma práxis psicossocial. In C. Antloga, K. T. Brasil, S. R. Lordello, M. S. Neubern, \& E. Queiroz (Eds.), Psicologia Clínica e Cultura Contemporânea 4 (pp. 37-52). Technopolitik.

Fanon, F. (1980). Em defesa da revolução africana. Sá da Costa Editora.

Fanon, F. (2008). Pele negra, máscaras brancas. EDUFBA.

Fanon, F. (2015). Os condenados da terra. Editora UFJF.

Faustino, D. M. (2015). "Por que Fanon? Por que agora?": Frantz Fanon e os fanonismos no Brasil [Tese de doutorado]. Repositório UFSCAR. https://repositorio.ufscar.br/handle/ ufscar/7123

Fórum Brasileiro de Segurança Pública [FBSP]. (2019). Anuário Brasileiro de Segurança Pública 2018. FBSP.

Gonçalves, D. A., Mari, J. J., Bower, P., Gask, L., Dowrick, C., Tófoli, L. F., Campos, M., Portugal, F. B., Ballester, B., \&
Fortes, S. (2014). Brazilian multicentre study of common mental disorders in primary care: Rates and related social and demographic factors. Cadernos de Saúde Pública, 30(3), 623632. https://doi.org/10.1590/0102-311X00158412

Instituto de Pesquisa Econômica Aplicada [IPEA], \& FBSP. (2019). Atlas da violência 2019. IPEA; FBSP.

Lacerda Júnior, F. (2017). Apresentação - Colocando a Psicologia contra a ordem: Introdução aos escritos de Ignacio MartínBaró. In I. Martín-Baró, Crítica e libertação na Psicologia: Estudos psicossociais (pp. 7-21, Organização, notas e tradução F. Lacerda Júnior). Vozes.

Martín-Baró, I. (1973). Antipsiquiatria y antipsicoanálisis. Estudios Centroamericanos - ECA, 28(293/294), 203-206.

Martín-Baró, I. (1990). La familia, puerto y carcel para la mujer salvadoreña. Revista de Psicología de El Salvador, 9(37), 265-277

Martín-Baró, I. (1996). O papel do psicólogo. Estudos de Psicologia, 2(1), 7-27.

Martín-Baró, I. (2011). Para uma psicologia da libertação. In R. S. L. Guzzo \& F. Lacerda Jr. (Eds.), Psicologia social para América Latina: O resgate da psicologia da libertação (pp. 101-120). Alínea.

Martín-Baró, I. (2017a). Guerra e saúde mental. In I. Martín-Baró, Crítica e libertação na Psicologia: Estudos psicossociais (pp. 251-270, F. Lacerda Júnior, Trad.). Vozes.

Martin-Baró, I. (2017b). O latino indolente: Caráter ideológico do fatalismo latino-americano. In I. Martin Baró, Crítica e libertação na Psicologia (pp. 173-203, F. Lacerda Júnior, Trad.). Vozes. 
Martin-Baró, I. (2017c). Um psicólogo frente à guerra civil em El Salvador. In I. Martin Baró, Crítica e libertação na Psicologia (pp. 233-250, F. Lacerda Júnior, Trad.). Vozes.

Martín-Baró, I. (2017d). O psicólogo no processo revolucionário. In I. Martín-Baró, Crítica e libertação na Psicologia: Estudos psicossociais (pp. 25-29, F. Lacerda Júnior, Trad.). Vozes.

Martins, K. O., \& Lacerda Júnior, F. (2014). A contribuição de Martín-Baró para o estudo da violência: Uma apresentação. Revista Psicologia Política, 14(31), 569-589. http://pepsic. bvsalud.org/scielo.php?script=sci_arttext\&pid=S1519-549X2 014000300010\&lng $=$ pt\&nrm $=$ iso
Marx, K. (2004). Manuscritos econômico-filosóficos. Boitempo Editorial.

Ministério da Saúde. (2018). Óbitos por suicídio entre adolescentes e jovens negros 2012 a 2016. Ministério da Saúde.

Prado Júnior, C. (2011). Formação do Brasil contemporâneo: Colonia. Cia das Letras.

Ribeiro, D. (2006). O povo brasileiro: A formação e o sentido do Brasil. Cia das Letras.

Smolen, J. R., \& Araújo, E. M. (2017). Raça/cor da pele e transtornos mentais no Brasil: Uma revisão sistemática. Ciência e Saúde Coletiva, 22(12), 4021-4030. https://doi.org/10.1590/1413812320172212.19782016 